\begin{tabular}{|l|l|}
\hline $\begin{array}{l}\text { 2. To: (Recoiving Organization) } \\
\text { Distribution }\end{array}$ & $\begin{array}{l}\text { 3. From: (Originating Organization) } \\
\text { I.S. Engineering }\end{array}$ \\
\hline $\begin{array}{l}\text { 5. Proj./Prog./Dopt.Div.: } \\
\text { SST Interim Stabilization }\end{array}$ & $\begin{array}{l}\text { 6. Design Authority/Design Agent/Cog. Engr.: } \\
\text { D.K. DeFord }\end{array}$ \\
\hline
\end{tabular}

8. Originator Remarks:

Saltwell Pumping Systems R.A.M. Analysis

11. Receiver Remarks:

\author{
11A. Design Baseline Document? $O$ Yes $O$ No \\ 11A. Design Baseline Document? $\bigcirc$ Yes $\bigcirc$ No
}

\section{Related EDT No.:}

$\mathrm{N} / \mathrm{A}$

7. Purchase Order No.:

$\mathrm{N} / \mathrm{A}$

9. Equip./Component No.:

$\mathrm{N} / \mathrm{A}$

10. System/Bkg./Facility:

Single-Shell Tanks

12. Major Assm. Dwg. No.:

$\mathrm{N} / \mathrm{A}$

13. Permit/Permit Application No.:

$\mathrm{N} / \mathrm{A}$

14. Required Response Date:

$\mathrm{N} / \mathrm{A}$

$15 . \quad$ DATA TRANSMITTED

(A) liem

(B) Document/Drawing No.

(C) Sheet (D) Rev.

(E) Title or Description of Data Transmitted

(F)

(G)

\begin{tabular}{|c|c|c|c|}
\hline $\begin{array}{c}\text { Approval } \\
\text { Desig- } \\
\text { nator }\end{array}$ & $\begin{array}{c}\text { Reason Trans- } \\
\text { mittal }\end{array}$ & $\begin{array}{c}\text { Origi- } \\
\text { nator } \\
\text { Dispo- } \\
\text { stion }\end{array}$ & $\begin{array}{c}\text { Receiv- } \\
\text { er } \\
\text { Dispo- } \\
\text { sition }\end{array}$ \\
\hline N/A & 1 & 1 & \\
\hline
\end{tabular}

\begin{tabular}{|l|l|}
\hline $\mathrm{N} / \mathrm{A}$ & 0 \\
\hline & \\
\hline & \\
\hline & \\
\hline & \\
\hline & \\
\hline & \\
\hline
\end{tabular}

Saltwell Pumping Systems

\section{R.A.M. Analysis}

\begin{tabular}{|l|l|}
\hline 1 & RPP -5129 \\
\hline & \\
\hline & \\
\hline & \\
\hline & \\
\hline & \\
\hline & \\
\hline
\end{tabular}

16.
Approval Designator (F) E, S, Q, D OR N/A (S'S'WHC-CM-3-5 Sec. 12.7)

17.

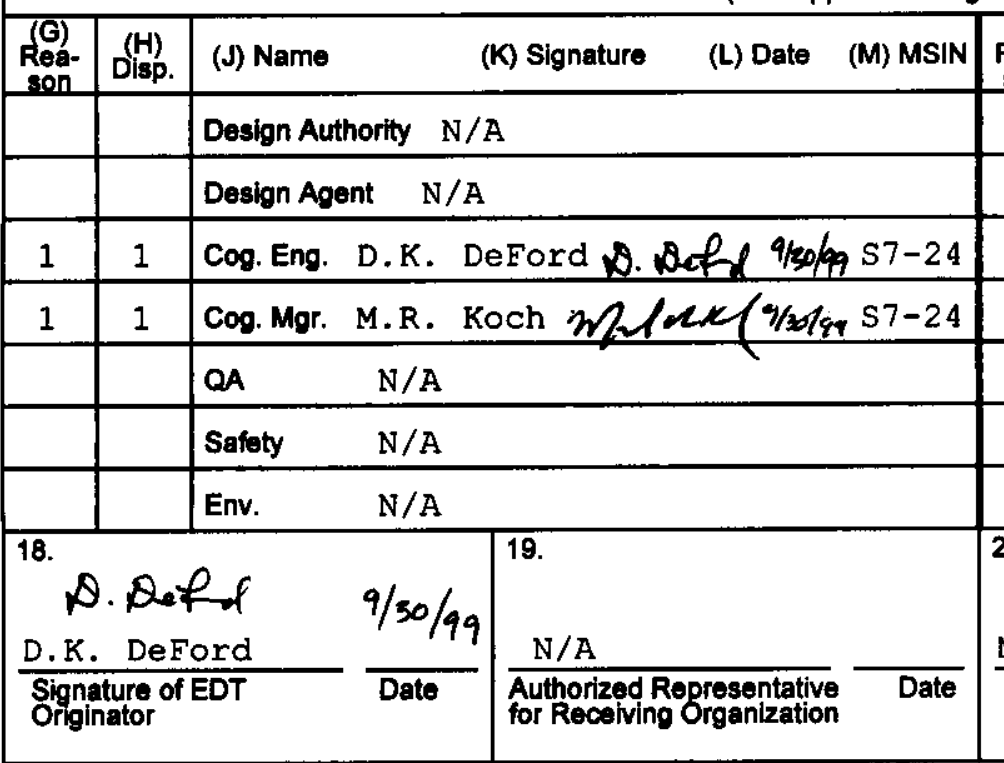

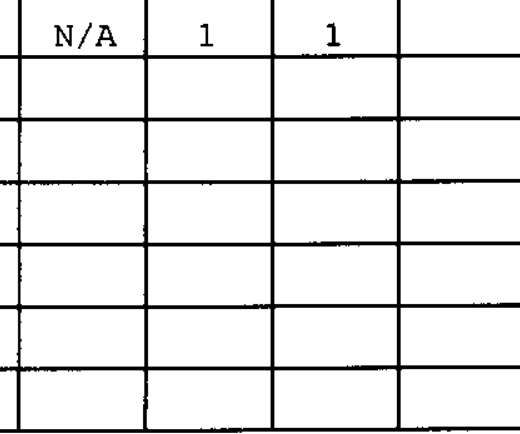

KEY 


\title{
SALTWELL PUMPING SYSTEMS R.A.M. ANALYSIS
}

D. K. DEFORD

Lockheed Martin Hanford Corporation

Richland, WA 99352

U.S. Department of Energy Contract DE-AC06-96RL13200

\author{
EDT/ECN: 624845 \\ Org Code: $74 \mathrm{DOO}$ \\ B\&R Code: N/A
}

UC: 2000

Charge Code: 103346

Total Pages: 46

Key Words: RPP; Single-Shell Tank; Interim Stabilization; Saltwell;

Reliability; Availability; Maintainability; Efficiency

Abstract: This study characterizes the reliability, availability, and maintainability of saltwell pumping systems based on historical data, and identifies recommendations to improve operating efficiency.

The report was initially issued as a letter report on September 9, 1999, reference no. NHC-9956343. The text is reproduced here with minor edits and without the appendices.

TRADEMARK DISCLAIMER. Reference herein to any specific commercial product, process, or service by trade name, trademark, manufacturer, or otherwise, does not necessarily constitute or imply its endorsement, recommendation, or favoring by the United States Government or any agency thereof or its contractors or subcontractors.

Printed in the United States of America. To obtain copies of this document, contact: Document Control Services, P.O. Box 950, Mailstop H6-08, Richland WA 99352, Phone (509) 372-2420; Fax (509) 376-4989.
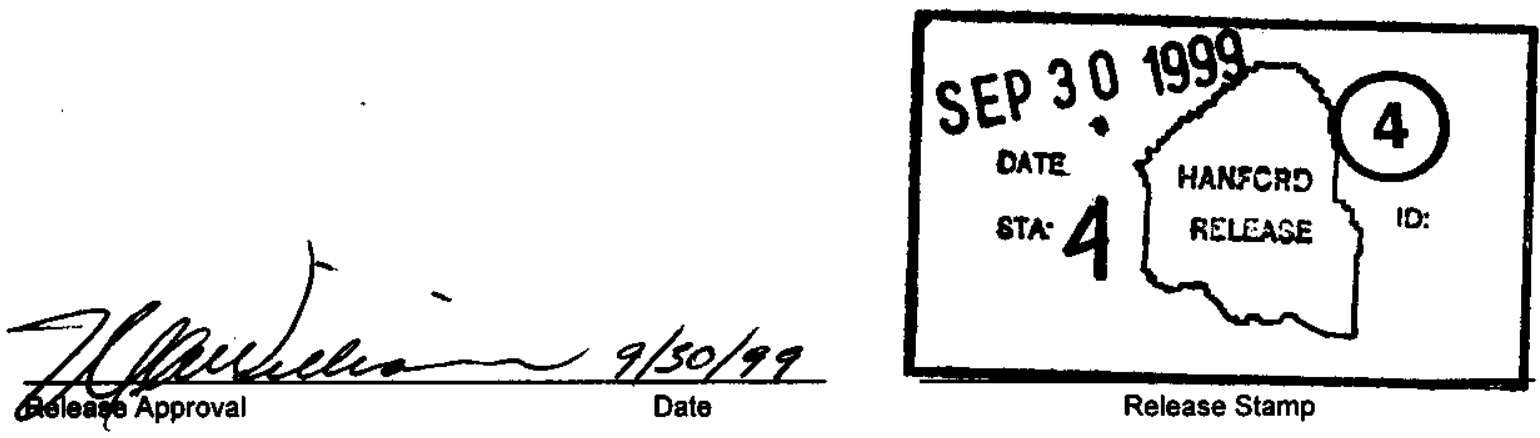

\section{Approved For Public Release}




\title{
SALTWELL PUMPING SYSTEMS RAM ANALYSIS
}

\author{
E. A. Pacquet \\ Numatec Hanford Corporation \\ D. K. DeFord \\ Lockheed Martin Hanford Corporation
}

August 1999 


\section{EXECUTIVE SUMMARY}

System availability (or operating efficiency) of saltwell pumping skids is a key parameter directly affecting the overall duration of the Interim Stabilization Project. Current planning is based on a projected operating efficiency of 45 to 50 percent. The purpose of this study was to characterize the reliability, availability, and maintainability (RAM) of saltwell pumping systems in order to identify means to achieve increased system availability and/or lower operating and maintenance costs.

The primary findings of the RAM analysis of saltwell pumping systems indicate that:

- The average operating efficiency of saltwell pumping systems from 1993 to 1999 is estimated at 42 percent.

- The average operating efficiency for tanks currently in operation and considered since June 1998 is 34 percent (as of June 27, 1999)

- Two elements clearly dominate as downtime contributors and offer the most potential for substantial and short term gain:

- DCRT transfers and maintenance estimated at 25 to 30 percent

- Saltwell equipment failures and maintenance estimated at over 20 percent

- Six systems contribute to 90 percent of equipment failure and maintenance related downtime

- A limited number (10) of individual components within these systems and specific failure modes have been identified as contributing to 70 percent of equipment failures and maintenance related downtime. These critical components clearly deserve priority for short-term increase of the operating efficiency.

As a result of these findings a number of recommendations specifically related to these elements as well as other aspects were identified in order to achieve increased system operating efficiency and/or lower operating and maintenance costs. These recommendations more specifically address: 
- Means to increase the reliability of these critical components or systems. Most of these recommendations imply relatively simple and practical actions such as alternative component specifications, modifications, improved fabrication control, installation, or testing.

- Various considerations related to the operation and maintenance process.

- Consideration of alternative pump technologies.

- The need to investigate the potential relaxation of safety requirements based on operational data and engineering analysis. 


\section{TABLE OF CONTENTS}

1.0 INTRODUCTION . .1

\subsection{OBJECTIVES}

1

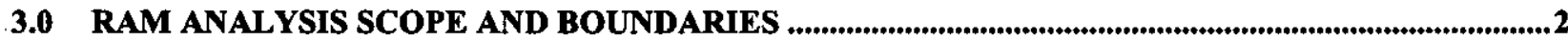

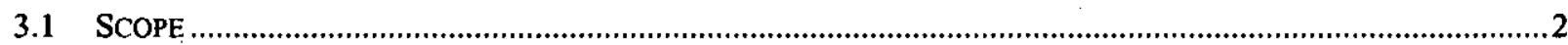

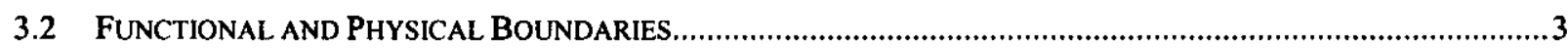

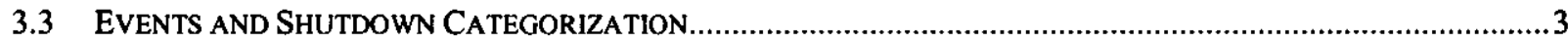

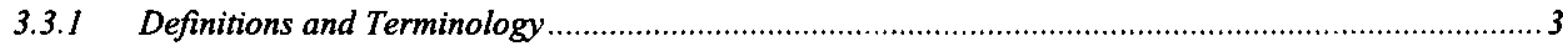

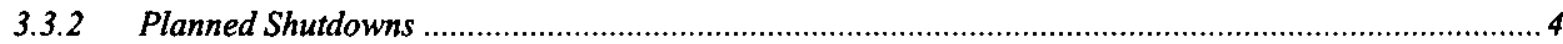

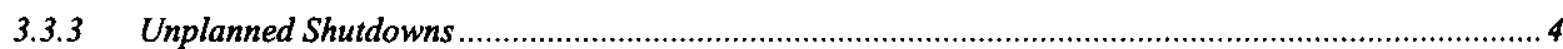

3.4 RESPECTIVE CONTRIBUTION OF DOWNTIME ELEMENTS BASEd ON PREVIOUS ESTIMATIONS ...........................5

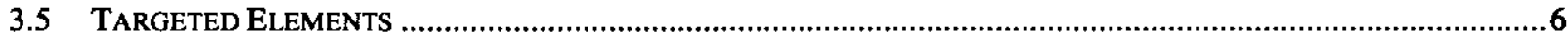

4.0 RAM ANALYSIS OVERALL APPROACH AND METHODOLOGY ..................................................

5.0 OPERATING EFFICIENCY DATA SUMMARY AND ANALYSIS ........................................................

5.1 SUMMARY OF RECENT PERFORMANCE

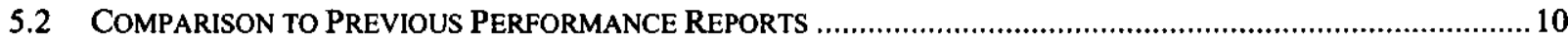

6.0 EQUIPMENT MAINTENANCE AND FAILURE ANALYSIS .............................................................

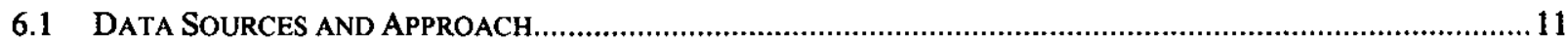

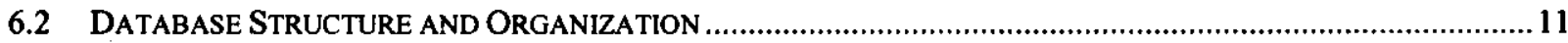

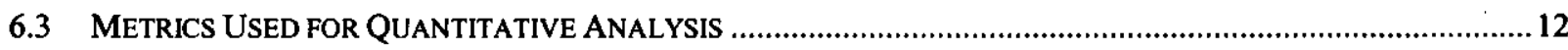

6.3.1 Event

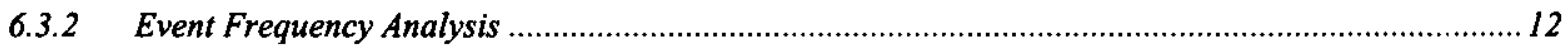

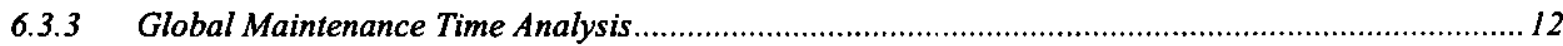

6.3.4 Availability and Downtime Contribution Analysis .....................................................................

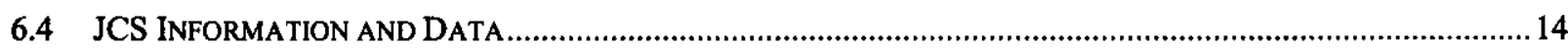

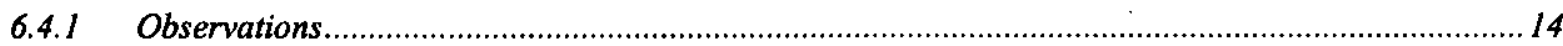

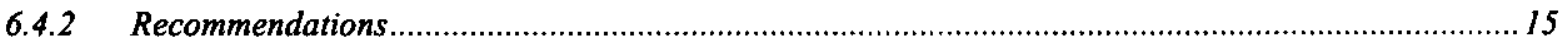

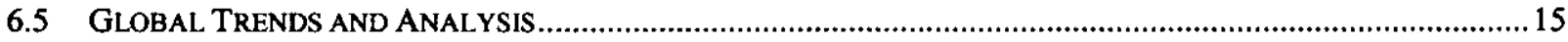

6.5.1 Frequency and Maintenance Time Distribution by System …….............................................. 15

6.5.2 Frequency and Maintenance Time Distribution by Component Type .............................................. 16

6.5.3 Critical Components Maintenance Frequency and Time Distribution ............................................ 16

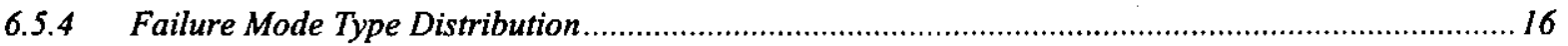




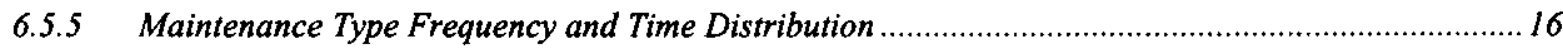

6.6 OPERATING EFFICIENCY AND DOWNTIME CONTRIBUTION ANALYSIS .......................................................... 17

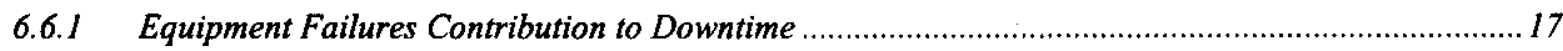

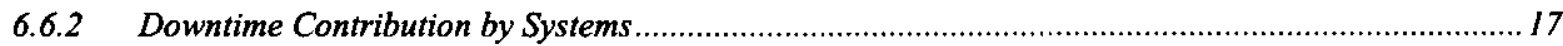

6.6.3 Critical Components Downtime Contribution ............................................................................

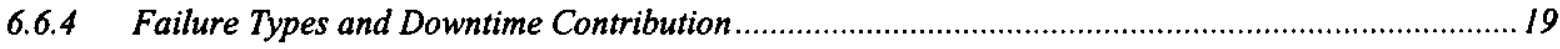

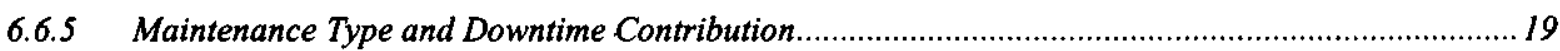

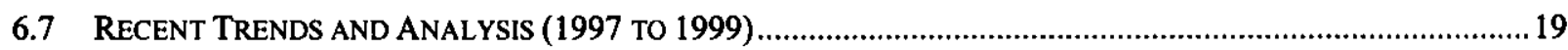

6.7.1. Global Maintenance Frequency and Time Distribution by Systems ...................................................20

6.7.2 Frequency and Downtime Contribution by Systems …….............................................................20

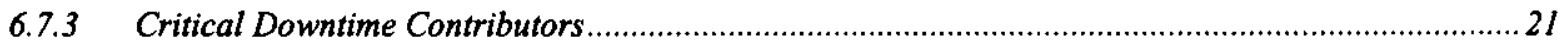

6.8 CRITICAL COMPONENTS AND FAILURE MODES - DISCUSSION AND RECOMMENDATIONS .............................21

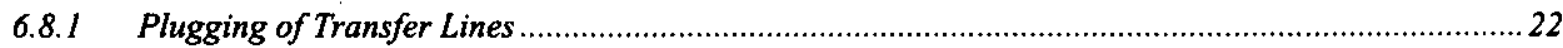

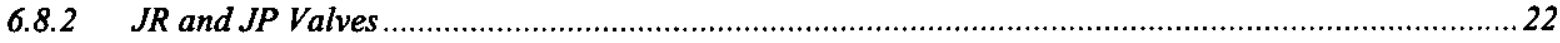

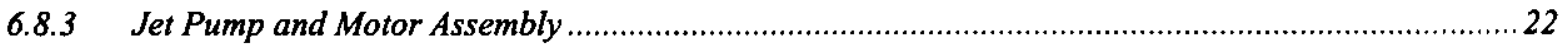

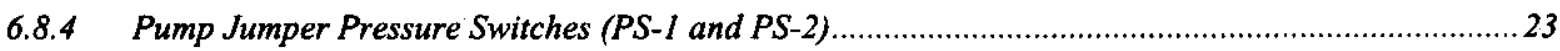



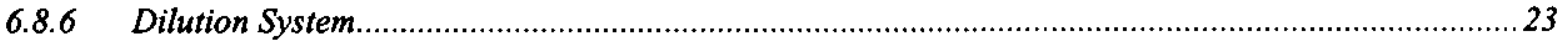

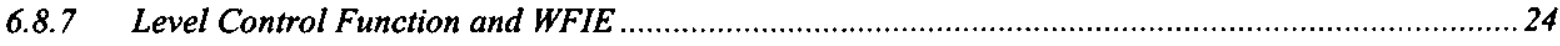

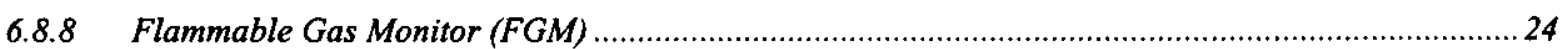

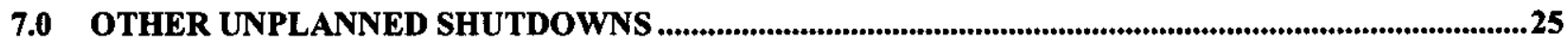

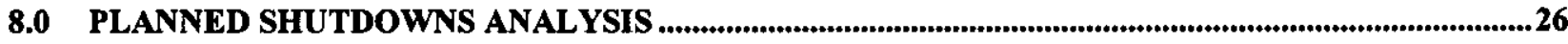

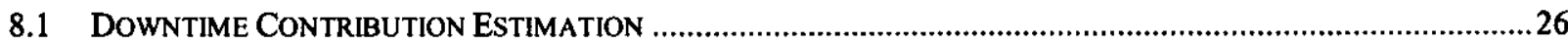

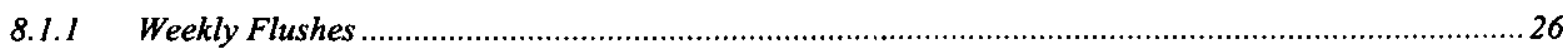

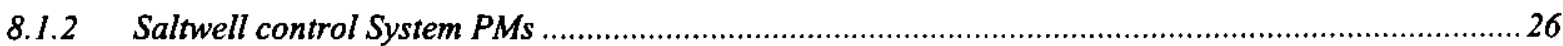

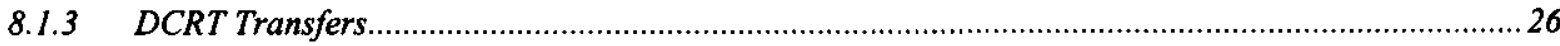

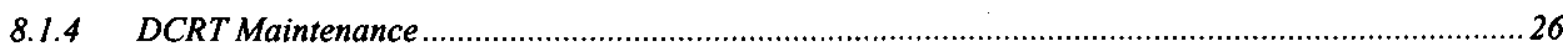

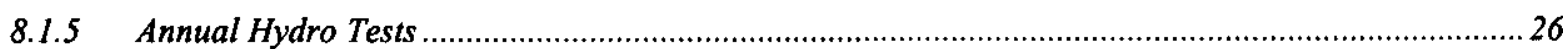

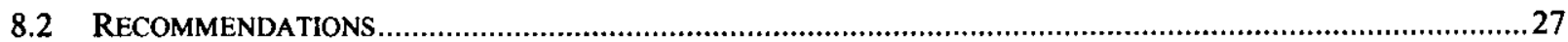

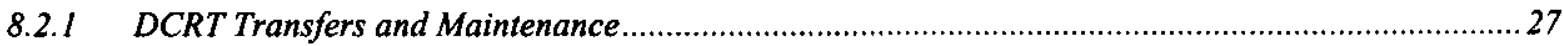

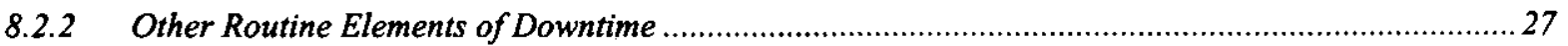

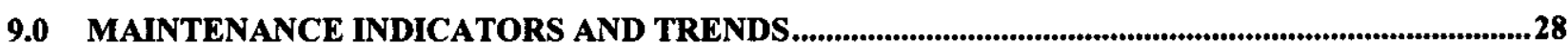

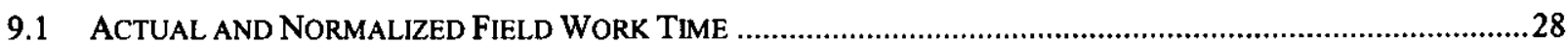

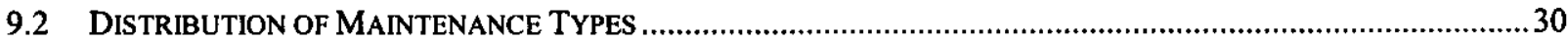

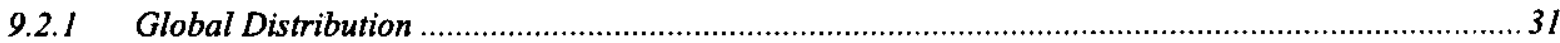


9.2.2 Maintenance Frequency and Time Distribution Across and Within the Different Phases ................. 3I

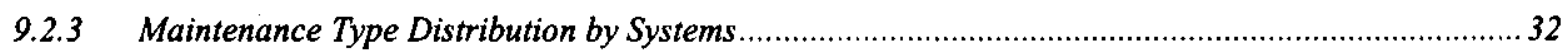

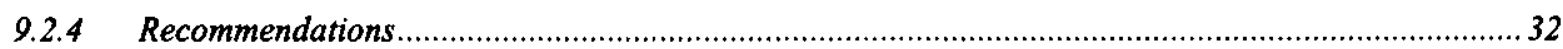

10.0 OPERATION AND MAINTENANCE PROCESS CONSIDERATIONS .......................................33

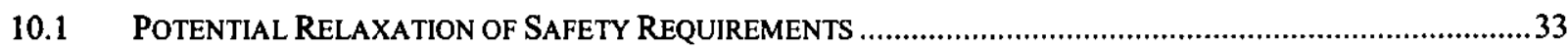

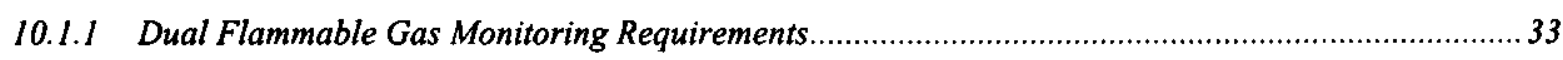

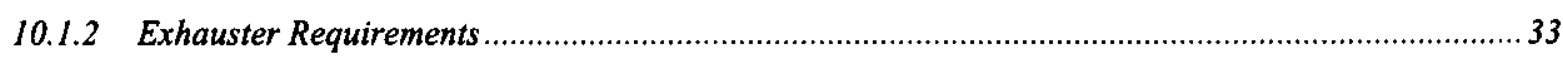

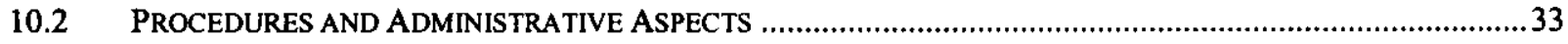

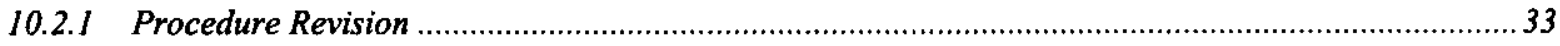

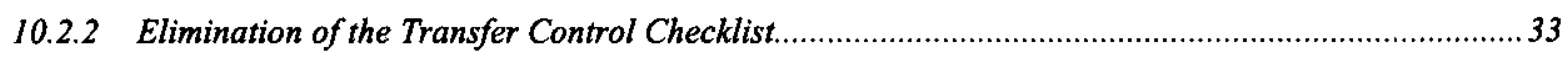

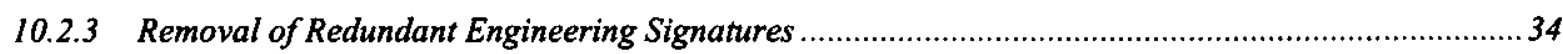

10.2.4 Eliminate the practice of field testing instruments for pump start-up where they are already in use by

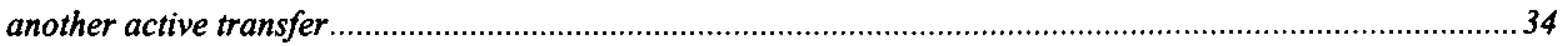

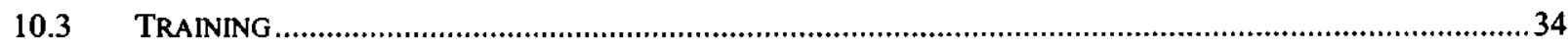

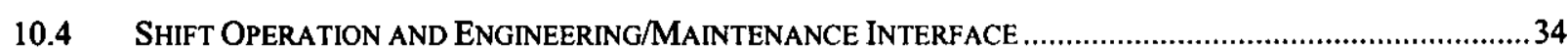

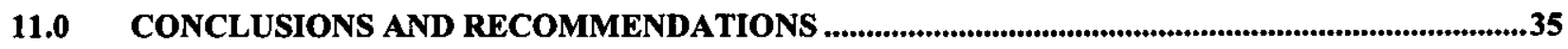

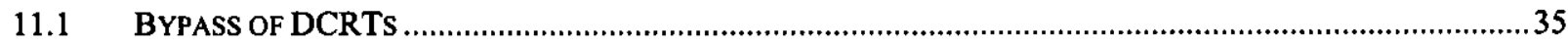

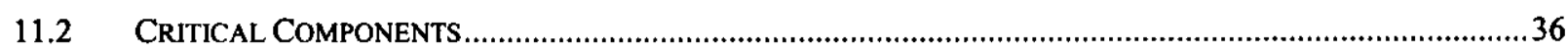

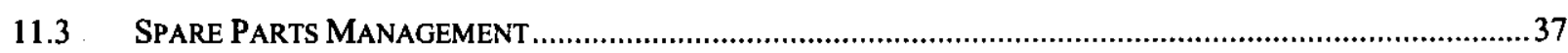

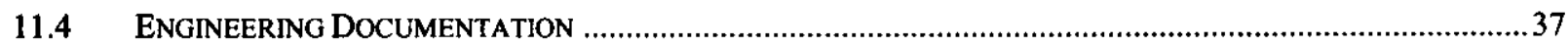

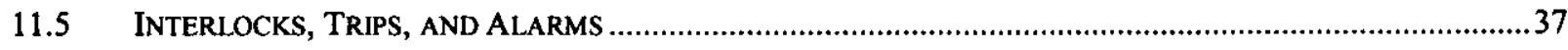

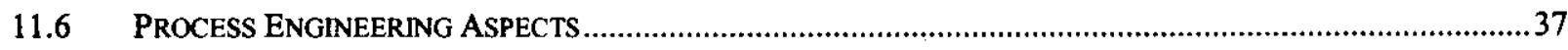

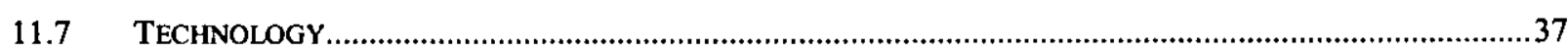

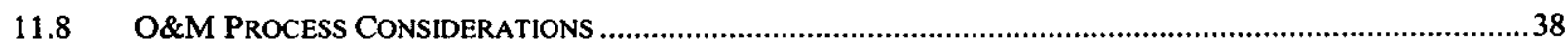

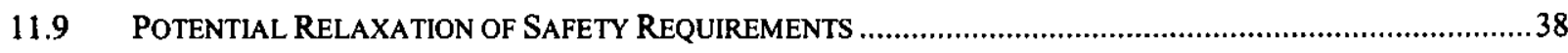

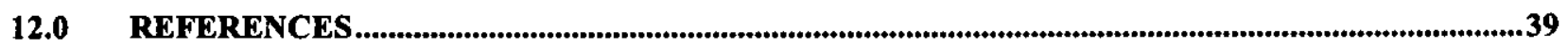




\subsection{INTRODUCTION}

Solid and liquid radioactive wastes are stored in 149 single-sell tanks (SSTs) at the Hanford Site. The charter of the Interim Stabilization (IS) Project is to reduce the potential for SST leakage to the vadose zone, by transferring as much drainable liquid as possible to newer double-shell tanks.

To date, 119 tanks have been declared to be interim stabilized, and 30 tanks remain to be stabilized. One of these tanks (C-106) will be stabilized by retrieving the tank contents. The remaining 29 tanks will be interim stabilized by saltwell pumping.

The saltwell pumping approach uses a central well screen and a low-capacity jet pump installed in the well to remove drainable liquid from the sludges and saltcakes. Liquid in the tank is driven to this central well by the pressure of the interstitial liquid within the bed (head height). To maximize the drainage rate, the liquid in the well is maintained at the lowest possible level. This ensures the maximum drainable liquid is removed as quickly as possible.

The Interim Stabilization (IS) Project currently plans to complete the interim stabilization and isolation of the 29 remaining tanks by February 2005 . The duration of the project is directly affected by the total system availability of the pumping systems. The current IS Project baseline assumes an average of 45 to 50 percent availability of the saltwell pumping systems. For tanks with long pumping durations, increased operating efficiency can result in dramatic improvements to the overall completion schedule and life-cycle cost savings.

The purpose of this study is to characterize the reliability, availability, and maintainability (RAM) of saltwell pumping systems in order to identify means to achieve increased system operating efficiency and/or lower operating and maintenance costs.

\subsection{OBJECTIVES}

The immediate objectives of this RAM analysis of saltwell pumping systems are:

- To identify and quantify significant downtime contributors based on an analysis of historical performance.

- To provide recommendations on how to achieve increased system operating efficiency and/or lower operating/maintenance costs.

The approach has been based primarily on three perspectives:

- An analysis of equipment failure modes and restoration time.

- A cursory review of operating and maintenance practices and methods.

- Identification of design, hardware, technology, or process optimization opportunities. 


\subsection{RAM ANALYSIS SCOPE AND BOUNDARIES}

The initial step of this study was to clearly establish the scope and boundaries of the analysis.

\subsection{Scope}

This RAM assessment is based on historical data and performance of saltwell systems. Existing maintenance and operational records were used. A more theoretical and predictive approach to the RAM analysis could have been used, but this implies the use of equipment failure rate development models, which do not specifically exist for saltwell systems. Hence the more practical approach based on an analysis of historical performance was selected.

In order to obtain a sufficiently large database representative of current constraints and practices applicable to Interim Stabilization, the time frame from 1993 to early June 1999 was considered. Evolutions over this period, such as equipment modifications and improvements were considered in order to isolate the most recent factors affecting the reliability, availability, and maintenance of saltwell systems. Single shell tanks (SSTs) stabilized prior to this period were not considered as they were clearly operated under a fundamentally different set of technical and regulatory criteria, constraints, and conditions.

A set of 24 SSTs were hence considered for this analysis:

- 13 tanks pumped from 1993 to 1997

$\begin{array}{ll}\text { BX-110 } & \text { C-102 } \\ \text { BX-111 } & \text { C-107 } \\ \text { BY-102 } & \text { C-110 } \\ \text { BY-103 } & \text { S-108 } \\ \text { BY-106 } & \text { S-110 } \\ \text { BY-109 } & \text { T-107 } \\ & \text { T-111 }\end{array}$

- 7 tanks currently in operation
S-102
SX-104
S-103
SX-106
S-106
$\mathrm{T}-104$
$\mathrm{T}-110$

- 4 tanks currently being prepared for operation in the near future

U-102

$\mathrm{U}-103$

$\mathrm{U}-105$

U-109 


\subsection{Functional and Physical Boundaries}

The analysis was primarily and intentionally focussed on the facilities, systems, and components directly operated and under the control of the IS Project. This includes saltwell pumping equipment and direct support systems. Facilities, systems and components associated with the transfer of waste to the double shell tanks via double contained receiver tanks (DCRTs) were only considered from the standpoint of their global contribution to system availability and operating efficiency.

A functional breakdown of the systems associated with the saltwell pumping function and their respective hardware boundaries were defined as follows:

- AS: Air Supply System

- DCRT: Double Contained Receiver Tank

- DS: Dilution System

- EIL: External Interlocks

- ES: Electrical Power Supply and Distribution

- EXH: Exhauster

- FGM: Flammable Gas Monitor

- HT: Heat Tracing System

- LD: Leak Detection

- PA: Jet Pump and Discharge Jumper Assembly and Saltwell Screen and Casing

- PCS: Pump Control Station

- PICS: Pumping and Control Skid

- TL: Transfer Lines

- WFIE: Level Control Function (i.e. dip tubes and weight factor instrument enclosure)

- WS: Water Supply

In the absence of equipment and instrument lists, individual components were identified and designated according to the P\&ID equipment identification nomenclature.

\subsection{Events and Shutdown Categorization}

\subsubsection{Definitions and Terminology}

The terms "System Availability", "Operating Efficiency", "Pumping Efficiency", and "Pumping Percentage" have been used interchangeably to report performance of saltwell pumping campaigns. Because these terms have been defined differently under the various administrations, it is somewhat difficult to compare historical performance from one pumping campaign to another (See Section 5).

For the purpose of this analysis the term "Operating Efficiency" (OE) will be used and defined as in the current IS Project Plan (Lewis 1999), as: 
"the number of actual operating hours of a given pump divided by the number of hours since the pump was started."

Inversely what is referred to as downtime in this report is simply:

$$
\text { Downtime }=1-\mathrm{OE}
$$

In this definition, it is recognized that even a perfect operational record will result in a percentage operating efficiency of less than a $100 \%$ because of the planned and routine shutdowns required as part of the pumping process.

Downtime is comprised of various elements as described in the following sections. The two broad categories are Planned Shutdowns, and Unplanned Shutdowns.

\subsubsection{Planned Shutdowns}

During each saltwell pumping campaign, the pump must be shut down periodically to accomplish several routine activities that support the pumping operations. The elements of planned/routine downtime include:

- Weekly Flushes: During saltwell transfers, procedures require the pump to be shut down no less than once per week to flush the transfer line to prevent the precipitation of solids and plugging of the lines. These weekly line flushes typically require one 8-hour shift per week.

- Saltwell Control System PMs:

Routine maintenance and calibration of the various components of the saltwell pumping control system requires an average of 160 hours per year.

- DCRT Transfers:

For those tanks pumping via a DCRT, periodic shutdowns are required to empty the receiver tank.

- Annual Hydro Tests:

The direct buried segments of underground transfer lines are required to be revalidated by hydro-testing every 12 months. This requires a one-week shutdown on average for a single tank. Multiple tanks pumping within the same transfer system (i.e. feeding the same DCRT) are tested concurrently where practical, but sometimes a pumping tank has to shut down to support testing for another tank.

\subsubsection{Unplanned Shutdowns}

In addition to the planned/routine downtime elements described above, there are a number of offnormal events or reasons that can lead to interruption of pumping during a campaign. These have been categorized as follows: 
- Saltwell equipment failures and resulting corrective maintenance.

- Abnormal or emergency conditions such as interlocks, trips and alarms, which require or induce an interruption of pumping and time to restore normal operating conditions.

- DCRT Maintenance.

- Operational restrictions due to external events or activities. These include a broad range of factors such as severe weather conditions (heat, cold, wind, lightning, range fires), interference with construction projects, other facility issues, and human actions related mishaps (e.g., procedural incidents causing stop of progress and requiring a recovery activity prior to restart).

- Administrative restrictions due to safety or regulatory issues. Since 1993 there have been a number of long term shutdowns related to these issues such as flammable gas issues, Ecology's concerns regarding flush water additions, etc.

\subsection{Respective contribution of Downtime Elements Based on Previous Estimations}

A previous analysis (DeFord 1998) estimated downtime contributing elements on the basis of global assumptions, estimates, and averages. This analysis was performed for planning purposes and establishing a target operating efficiency for future campaigns. Although it contains some level of uncertainty, it was used as an initial guide for targeting the elements of significance, and where improvement can reasonably be expected. Table 3-1 summarizes the results of this analysis.

Table 3-1

Saltwell Pumping Downtime Breakdown Estimate (DeFord 1998)

\begin{tabular}{|l|c|c|}
\hline \multicolumn{1}{|c|}{ Elements of Downtime } & With DCRT $^{(\mathbf{)}}$ & No DCRT $^{(2)}$ \\
\hline ROUTINE SHUTDOWNS: & & \\
\hline Weekly Flushes & $4.8 \%$ & $4.8 \%$ \\
\hline Saltwell System PMs & $1.8 \%$ & $1.8 \%$ \\
\hline DCRT Transfers & $10.3 \%$ & NA \\
\hline Annual Hydro Tests & $2.7 \%$ & $2.7 \%$ \\
\hline Adjustment for Overlap & $(2.1 \%)$ & $(0.9 \%)$ \\
\hline Maximum Possible Operating Efficiency (1 - downtime) & $17.5 \%$ & $8.4 \%$ \\
\hline
\end{tabular}


RPP-5129

\begin{tabular}{|l|c|c|}
\hline NON-ROUTINE SHUTDOWNS: & & \\
\hline DCRT Maintenance & $15 \%$ & NA \\
\hline Component Failures \& Interlocks & $20 \%$ & $20 \%$ \\
\hline External Activities & $1.4 \%$ & $1.4 \%$ \\
\hline Safety \& Regulatory Issues & $5 \%$ & $5 \%$ \\
\hline Adjustments for Overlap & $(3 \%)$ & $(1 \%)$ \\
\hline Non Routine Subtotal: & $38.4 \%$ & $25.4 \%$ \\
\hline Adjustment for Routine/Non-Routine Overlap Combined Subtotal: & $(5.8 \%)$ & $(1 \%)$ \\
\hline Maximum Achievable Operating Efficiency (1 - Downtime) & $50.1 \%$ & $32.8 \%$ \\
\hline Additional Risk Factors: & $\mathbf{4 9 . 9 \%}$ & $\mathbf{6 7 . 2 \%}$ \\
\hline Total Downtime: & $20 \%$ & $15 \%$ \\
\hline Projected Operating Efficiency (1 - Downtime) & $70.1 \%$ & $47.8 \%$ \\
\hline
\end{tabular}

(1) Assuming transfer via DCRT

(2) Bypass of DCRT

It should be noted that the global operating efficiency calculated from these estimates was comparable and consistent with the actual average operating efficiency experienced with the tanks in operation at that time (T-104, T-110, SX-104, SX-106). Section 5 of this report discusses in more detail the historical performance data of the various tanks.

\subsection{Targeted Elements}

Based on the results discussed above, it was decided that this study should primarily focus on the two most significant downtime contributors over which substantial short term improvements could reasonably be anticipated:

- Saltwell Equipment Failures and Maintenance (20\%)

- DCRT Transfers and Maintenance (25\%)

No analysis was attempted regarding elements over which the IS Project has no direct control such as external, safety \& regulatory, environmental, and human action related shutdowns and delays. Regarding safety \& regulatory issues, it should be noted that language included in the current IS Project Management Plan (Lewis 1999) states that once pumping has been initiated in a given tank, then no further changes to the safety and regulatory baseline will be applied to that tank. 


\subsection{RAM ANALYSIS OVERALL APPROACH AND METHODOLOGY}

Upon identification of the scope, functional and physical boundaries, and elements primarily targeted in this analysis, the approach summarized below was used.

- Operating Efficiency Data Summary and Analysis

The objective is to update operating efficiency data based on historical performance, compare to previous estimations and analyze whether any notable trends appear over time. Other parameters contributing to the overall pumping schedule duration are also discussed.

- Equipment Maintenance and Failure Analysis The objective of this section is to identify and quantify the critical systems, components and failure modes affecting the reliability, availability, and maintenance of saltwell systems, based on an analysis of maintenance records (JCS data). Historical and more recent trends are identified for these systems and components from the perspective of their contribution to the overall maintenance effort, as well as to the operating efficiency (downtime contributing components and failure modes). Recommendations in order to improve the reliability of these systems and components are provided.

- Planned Shutdowns Analysis Identification of the various planned shutdowns and quantification of their respective downtime contributors, in order to identify means to achieve increased operating efficiency and/or lower operation and maintenance costs.

- Maintenance Indicators and Trends Maintenance practices are more specifically examined in this section, on the basis of indicators and trends identified during the review of JCS data.

- Operation and Maintenance Process

Various aspects of the O\&M process are examined in order to identify means to achieve increased operating efficiency and/or lower operating and maintenance costs.

- Conclusions and Recommendations

Summary and prioritized list of recommendations identified in this study. 


\subsection{OPERATING EFFICIENCY DATA SUMMARY AND ANALYSIS}

\subsection{Summary of Recent Performance}

As discussed in Section 3.3.1, the notion of operating efficiency has been defined differently under various administrations, rendering somewhat difficult a direct comparison of historical performance from one campaign to another.

Based on the most recent definition in effect since June 1, 1998, the overall operating efficiency for the tanks in operation as of the end of June 1999 is reported as follows:

Table 5-1

Operating Efficiency from June 1, 1998 to June 27, 1999

\begin{tabular}{|c|c|}
\hline & $\%$ OE \\
\hline T-104 & 38 \\
T-110 & 28 \\
SX-104 & 33 \\
SX-106 & 32 \\
S-102 & 21 \\
S-103 & 49 \\
S-106 & 57 \\
\hline Average & 34 \\
\hline
\end{tabular}

It should be noted that this average is based on a relatively short period of time and includes three tanks started very recently. Hence, it only provides a "spot" indication.

Table 5-2 provides operating efficiency data for the time frame and set of tanks considered in this study. Tanks S-103 and S-106, which started in May and June 1999, were excluded. Data considered over this longer and somewhat more representative time period globally shows that:

- The mean operating efficiency is $39 \%$ based on an arithmetic average.

- The mean operating efficiency is $42 \%$ based on an average weighed by the individual campaign duration of the tanks.

- The trend over time, based on a rolling average, indicates a global increase and peak of the operating efficiency up until the end of 1998.

- There is a slightly decreasing trend over more recent time. 


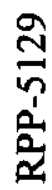

\begin{tabular}{|c|c|c|}
\hline 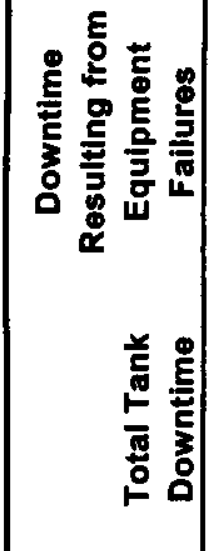 & 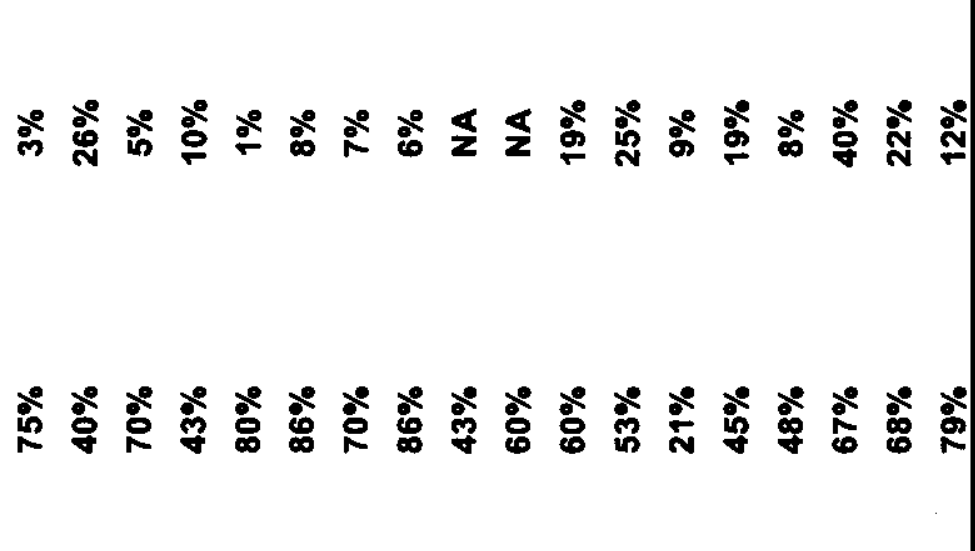 & ஃ̊ ㅇํㅇ \\
\hline
\end{tabular}

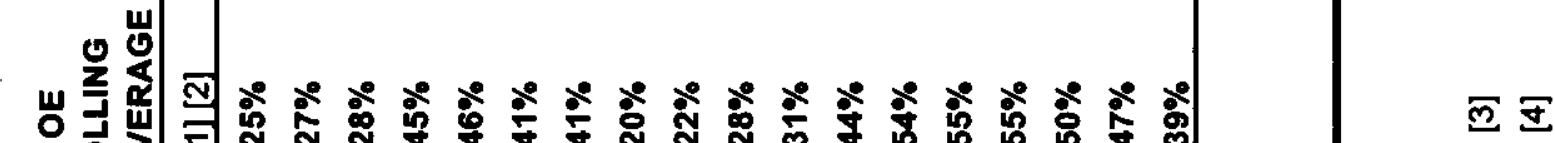

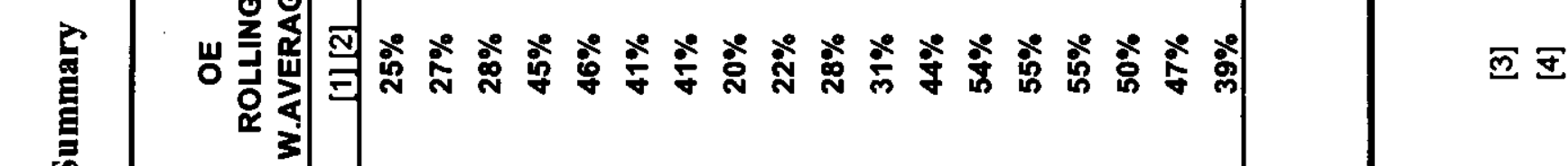

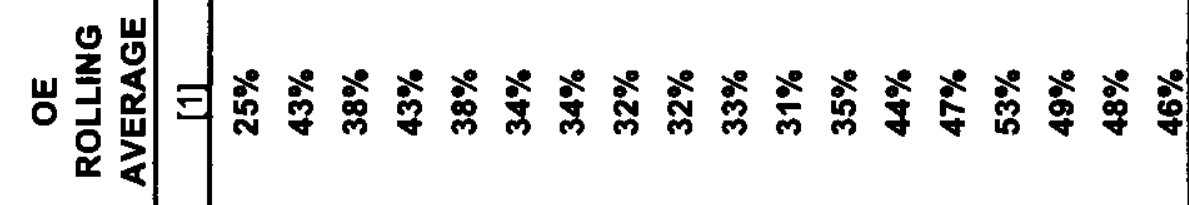

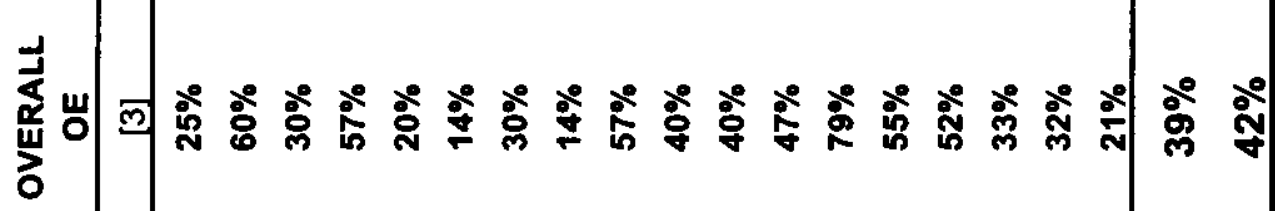

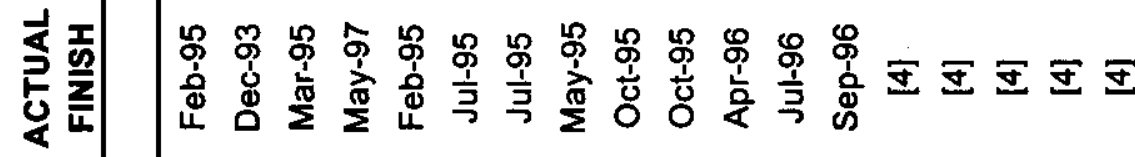

몽 몽

$\begin{array}{lll}8 & 8 & 5 \\ 1 & 0 & 1 \\ 1 & 1 & 0 \\ 2 & 0 & 4\end{array}$

ட山 ஜ

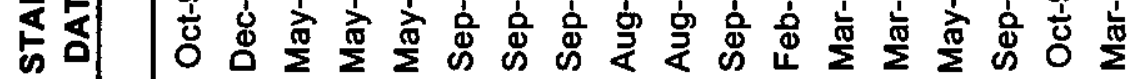

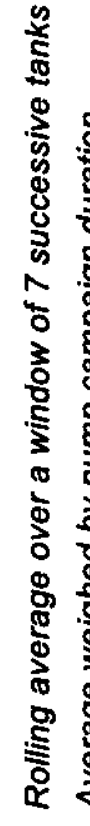

$a$

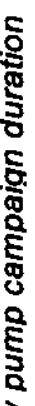

ᄒे

$\stackrel{8}{\frac{9}{2}}$

के

年

$\stackrel{9}{8}=\sqrt{2}$ 


\subsection{Comparison to Previous Performance Reports}

Higher values have generally been reported for operating efficiency in the past, but these values have been based on different criteria than the current campaign. For example, most historical values would be overstated in terms of the current definition, in that they exclude from the "elapsed time" calculations any significant blocks of time during which saltwell pumping was precluded by factors considered beyond the control of the IS program, such as DCRT corrective maintenance, construction interruptions, and safety or regulatory stand downs.

The generally accepted "mean operating efficiency" for all tanks pumped prior to 1994 as reported by Vasquez (1994) was $60 \%$ overall. The tanks included in this data were pumped under a less rigorous authorization envelope, resulting in higher operating performance. Shutdowns occurred primarily for problems with the components of the pumping system itself, and rarely for external reasons. The pumping systems have also become more complex with additional components (flammable gas monitors, exhausters, dilution system), controls, and interlocks increasing the probability of a shutdown due to component failure. Even so, this figure is considered to be overstated, in that several tanks are included in the average at $100 \%$ efficiency, after having been pumped for only a very short time. Although a thorough reevaluation of the original data was not attempted, an approximate weighted average based on volume pumped results in a revised historical performance value of only $47 \%$.

For the period 1993-1997, the mean operating efficiency was $41 \%$ for the 14 tanks pumped during that period. However, applying a weighted average on volume pumped results in a revised value of $35 \%$. These more recent estimates are generally consistent with the data presented in Section 5.1. 


\subsection{EQUIPMENT MAINTENANCE AND FAILURE ANALYSIS}

\subsection{Data Sources and Approach}

The primary and initial sources of information and data considered for equipment maintenance and failure analysis were the field work packages and routine work requests accessible through the Job Control System (JCS). For this purpose, all JCS work packages related to saltwell pumping systems over the considered time frame were included. Over 350 work packages were hence retrieved from the IS/CPO, 200 East and 200 West JCS servers. All types of maintenance work were considered with the exception of routine and planned preventive maintenance (PMs) (see Section 7.0). The maintenance types considered are categorized as follows:

- Corrective Maintenance (CM)

- Non Routine Preventive Maintenance (PM)

- Modifications (MOD)

- Operations Special Procedure (OSP)

- Non routine/unplanned functional tests, settings, adjustments, and calibrations (T\&Cal)

The information and data obtained from the JCS packages were then organized and structured in a database (Excel spreadsheet format) allowing the identification of notable trends or ratios on a statistical basis and according to criteria and parameters described in Section 6.2.

The various trends and ratios identified (i.e. critical components and failure modes) were then interpreted and analyzed with IS Engineering and Maintenance staff in order to identify recommendations.

\subsection{Database Structure and Organization}

Data and information from the JCS work packages were organized according to various categories of interest from the perspective of a RAM analysis. These primarily include for each individual event (i.e. a JCS work package or a specific work item within a package, when multiple activities are contained within this package):

- Work item description

- Failure mode description (when applicable)

- Downtime contributors designation in order to differentiate failures and/or work occurring during:

- pumping preparation

- pumping and resulting in downtime 
- pumping but without interruption of pumping

- post-pumping or isolation phases

- Farm or tank

- Functional system

- Component type

- Failure mode type (Process, Electrical, I\&C, Mechanical)

- Maintenance type (CM, PM, MOD, OSP, T\&Cal)

- Field Maintenance/work duration

\subsection{Metrics Used for Quantitative Analysis}

In order to obtain a quantitative analysis, a number of simple parameters and metrics were used.

\subsubsection{Event}

An event is to be understood in the broad sense of a specific system/equipment failure mode or a specific type of maintenance action. An event is generally described by a single JCS work package. Some packages containing multiple work items constitute as many multiple events.

\subsubsection{Event Frequency Analysis}

The notion of event frequency reflects how often a given type of event occurs. Hence the frequency is calculated as the number of times this specific event occurred divided by the total number of events globally considered. If for instance, the failure of a valve limit switch occurred 5 times out of a total of 500 events considered, then the frequency of this specific failure will be $1 \%$.

\subsubsection{Global Maintenance Time Analysis}

The significance of a specific type of event can be characterized by the associated consequences in terms of maintenance effort (i.e. time, resources, cost.) required to either prevent or correct this specific event. For the purpose of this analysis, global field maintenance time (i.e.: Time interval during which a package is open for fieldwork; effective field work being only a fraction of this time interval) was selected as the common measure of the effort associated to a type of event and its relative importance. In absolute terms, the global maintenance effort would have to combine time for work package preparation and closure, procurement, resources, and cost. For a relative comparison of events however, more specifically aimed at quantifying system availability and downtime, critical systems/components, or maintenance trends, global field maintenance time was considered to be a representative and sufficient measure. Global field 
maintenance time was calculated for each event as the time between fieldwork release and fieldwork completion as indicated in the corresponding JCS work package.

In a number of isolated cases it was clear that the actual work time was excessively long and not representative of what it would normally take to implement the maintenance action. In those isolated cases (predominately during the pump preparation phase) the actual work time was normalized (i.e. corrected to a more realistic duration) in order to avoid any statistical bias. It was found that these unusually long durations during which a package was left open for fieldwork, rather than being worked in the field, were generally linked to external circumstances or redirection of resources to higher priority tasks.

It should finally be noted and understood that in the global maintenance analysis, maintenance time includes all types of maintenance work types and phases as described in Section 6.1 with the exclusion of regularly planned preventive maintenance actions. These were quantified separately. There is no discrimination in global maintenance time between the various pumping phases (pre, during, post). Hence, global maintenance time should not be confused with downtime.

Downtime is a specific type and a subset of global maintenance time, applicable to events that interrupt pumping. Downtime contributing events have been specifically addressed and quantified separately as described in the following section.

\subsubsection{Availability and Downtime Contribution Analysis}

Events and factors contributing to downtime (i.e. inducing a shutdown of pumping) were specifically identified and quantified. The measure used here is simply downtime (also referred to as restoration or recovery time). In essence, the duration of the shutdown induced by a specific event (e.g.: component failure and time to get back on line). It should be noted that all equipment failures occurring during pumping do not necessarily induce downtime, as some components or systems can be "fixed" while pumping. Hence, a distinction was made between downtime contributors and non-contributors occurring during a pumping campaign.

It should be noted again that routine and planned shutdowns (e.g. PMs, weekly flushes, DCRT transfers, etc.) are not included in the quantification of downtime contribution based on JCS data (i.e., primarily equipment failures). Routine and planned shutdowns were quantified differently and specifically addressed in Section 7.0.

Similarly to global maintenance time, downtime for a given event is based on JCS package information. Downtime, however, was rarely corrected for an ideal situation (i.e. normalized) as it is assumed that the urgency of restoring a skid to operation is in most cases treated as high priority in terms of resource allocation.

Once again for the purpose of simplification and relative comparison, total downtime was calculated for each event as the time between fieldwork release and fieldwork completion as indicated in the corresponding JCS work package. This simplification underestimates the absolute downtime contribution estimated on this basis. 


\subsection{JCS Information and Data}

A number of observations should be made regarding the quality and limitations of JCS information from the perspective of this analysis.

\subsubsection{Observations}

The JCS is primarily a software-based tool ensuring adequate planning of fieldwork, necessary reviews and approvals prior to execution, tracking, and traceability. From this perspective it is a well designed and efficient tool. From the review of over 350 individual work packages, from 1993 to present for this analysis, it is apparent that the use of the system has significantly improved over time. Notable trends over time include:

- A significantly optimized and timely preparation and approval process

- Resource loaded estimates tend to be closer to actual expenditures

- The rigor, quality, and consistency of the various information fields has generally improved

- Identical work activities seem to take less time than they use to.

From the perspective of this study, however, some limitations were encountered:

- Packages related to an equipment failure are rarely very explicit as to the failure mode and the root cause of the failure. A typical package will describe the symptoms and a statement that work is completed with little other information. In some cases the description of the resolution actions allows deduction of the failure mode.

- Varying and sometimes inconsistent levels of quality were found in the documentation of information in the packages (e.g.: work type, description of problem, resolution, etc.). Some imperfections seem to subsist. Information fields are in some instances omitted or incorrectly designated.

- It is not apparent that useful operational experience and observations during equipment failures or problems are fed back in a systematic and detailed manner to the engineering and maintenance groups.

- As mentioned earlier, the duration during which a JCS package is open is not always indicative of the actual fieldwork time. Hence in a number of cases some correction and judgement was required in estimating field maintenance time. 
- Two recommendations regarding an enhanced use of the JCS data and information have come to light during the data processing phase of this analysis. These are described in the following sections.

\subsubsection{Recommendations}

Further and enhanced use of JCS data could easily be obtained from two perspectives:

1. A number of useful indicators regarding maintenance performance and organization can be tracked based on historical trending of JCS data. These indicators are more explicitly described in Section 9 . This could possibly be implemented beyond IS maintenance activities.

2. The RAM database developed for this analysis could be automated, refined and maintained to offer permanent and useful trending capabilities from the perspective of the RAM of saltwell systems. These trends would allow easier identification and focus on significant hardware problems.

Both of these recommendations however imply a consistent documentation of data and information in the work packages.

\subsection{Global Trends and Analysis}

The objective of this section is to identify critical systems, components, and failure modes from the global perspective of reliability and associated maintenance effort. Hence all events over the period of 1993 to June 1999 have been considered combining all types of maintenance work activities (with the exclusion of routine preventive maintenance) associated to saltwell systems. The metric used for quantification is maintenance fieldwork duration as defined in Section 6.3.

In order to establish notable trends, data and information were considered:

- by individual tank

- by system type

- by component type

- by failure mode type

- by maintenance type

Note: The (Figures) referred to in this section are graphs produced from the Excel database, which were included as an attachment to the letter report. They do not appear in this document.

\subsubsection{Frequency and Maintenance Time Distribution by System}

The four top "troublemakers" both in terms of frequency and maintenance time consumption clearly stand-out as the level control function, jet pump and jumper, flammable gas monitor, and air supply system, with over $65 \%$ of all maintenance actions and over $60 \%$ of the maintenance 
fieldwork time dedicated to these systems. Further sections will discuss in more detail the exact nature and content of the maintenance actions performed on these systems. (Figure 6-1)

As one might expect the jet pump and discharge jumper assembly as main process system with in tank and in pit equipment, clearly stands out as single maintenance time consumer (43\%).

A special note should finally be made regarding the leak detection and transfer line systems which both have a relatively low frequency (i.e.: they have not often required attention) but have comparatively consumed a significant amount of maintenance time (or effort).

\subsubsection{Frequency and Maintenance Time Distribution by Component Type}

(Figure 6-2) ranks component types (rather than specific components) in terms of their maintenance frequency and time distribution. It should be noted that with the exception of the jet pump, I\&C and electrical components clearly dominate maintenance actions.

\subsubsection{Critical Components Maintenance Frequency and Time Distribution}

A more detailed analysis of JCS records indicates that fifteen individual components or specific portions of systems have historically contributed to $70 \%$ of the overall maintenance time consumption. (Figure 6-3)

\subsubsection{Failure Mode Type Distribution}

Mechanical and I\&C failure modes have historically dominated both in terms of maintenance frequency and time distribution. Electrical and process failures are somewhat more marginal. Process failures are essentially characterized by a single type of occurrence, which is the plugging of transfer lines. (Figure 6-4)

\subsubsection{Maintenance Type Frequency and Time Distribution}

$60 \%$ of all maintenance (with the exclusion of regular PMs) performed on saltwell systems is corrective maintenance. Modifications and upgrades $(26 \%)$, followed by operations special procedures $(8 \%)$, non-routine preventive maintenance $(5 \%)$, and non-routine tests, settings, adjustments, and calibrations (3\%) constitute the remainder of the maintenance effort.

(Figures 6-5 and 6-6)

A special note should be made regarding the absence of predictive maintenance. Section 9 discusses in further detail the interpretation and analysis of maintenance practice indicators and trends identified in this study. 


\subsection{Operating Efficiency and Downtime Contribution Analysis}

An analysis similar to the one described in Section 6.5 (i.e., global and historical) was also performed with a focus on downtime contributing events and operating efficiency. Hence this analysis is restricted to equipment failures and maintenance occurring during pumping and directly contributing to downtime.

\subsubsection{Equipment Failures Contribution to Downtime}

(Figure 6-7) illustrates the downtime contribution of equipment failures for each of the individual tanks considered in this study as well as the average contribution.

The following results are worthy of interest:

- The average global operating efficiency of saltwell systems considered for this study is $42 \%$ (i.e., $58 \%$ downtime). This average is weighed according to the individual tank pumping durations. (See Section 5)

- Over $35 \%$ of total downtime (in relative terms) are attributable to equipment failures.

- This represents over $20 \%$ (in absolute terms) of the operating efficiency (or $20 \%$ of total saltwell system availability) lost to equipment failures alone.

It should be noted that this figure is underestimated due to the fact that fieldwork time has been used as the measure of downtime in this study, and that time spent troubleshooting for identification of a specific equipment failure, preparation of a JCS work package, and closure of actions after fieldwork and prior to restart are not accounted for.

This estimation however is consistent with previous order of magnitude estimates (DeFord 1998) and confirms equipment failures as notable downtime contributors worth considering in view of increasing operating efficiency.

\subsubsection{Downtime Contribution by Systems}

Five individual systems since 1993 have more specifically contributed to downtime associated to equipment failure. (Figure 6-8) These five systems alone have constituted close to $90 \%$ of this downtime as follows: 
RPP-5129

Table 6-1

Downtime Contribution by Systems

\begin{tabular}{|l|c|c|}
\hline \multicolumn{1}{|c|}{ System } & Downtime (\%) & Frequency (\%) \\
\hline - $\quad$ Pump and Jumper Assembly (PA) & 49.2 & 35.0 \\
- $\quad$ Plumgging of Transfer Lines (TL) & 14.1 & 22.5 \\
- Level Control (WFIE) & 10.5 & 4.4 \\
- Dilution System (DS) & 9.0 & 13.8 \\
\hline Total & 6.2 & 8.1 \\
\hline
\end{tabular}

It is evident that multiple components and failure modes within each of these systems have contributed in various ways and degree to this downtime, and that some failure modes may not reflect the current situation as they may have been eliminated through modifications and improvements. These aspects are discussed further in this study.

\subsubsection{Critical Components Downtime Contribution}

Four specific components have historically caused over $50 \%$ of equipment failure downtime, while having a comparatively low frequency failure: (Figures 6-9 and 6-10)

Table 6-2

Critical Components Downtime Contribution

\begin{tabular}{|l|c|c|}
\hline \multicolumn{1}{|c|}{ Critical Components } & Downtime (\%) & Frequency (\%) \\
\hline - Jet Pump, Foot Valve, and Motor Assembly & 25 & 11 \\
- Plugging of Transfer Lines & 11 & 4 \\
$\begin{array}{l}\text { Pump discharge Jumper Fittings and } \\
\text { Connections }\end{array}$ & 9 & 8 \\
Pump discharge Jumper Valves and Limit \\
\begin{tabular}{l} 
Switches \\
\multicolumn{1}{|c|}{ Total }
\end{tabular} & 9 & 8 \\
\hline
\end{tabular}


A surprisingly limited number of individual components (14) has accounted for $87 \%$ of this downtime. The exact nature of failure modes associated to these components is discussed in more detail in Sections 6.7 and 6.8.

\subsubsection{Failure Types and Downtime Contribution}

Mechanical (45\%) and I\&C (25\%) failures clearly dominate both in terms of frequency and downtime contribution, followed by process $(15 \%)$ and electrical failures $(15 \%)$. This distribution is very similar and consistent with the global distribution observed for all types of maintenance. (Figure 6-11)

\subsubsection{Maintenance Type and Downtime Contribution}

As might be expected corrective maintenance actions ( $70 \%)$ largely account for downtime contributing maintenance, followed by operations special procedures (15\%) such as unplugging of transfer lines, jet pump replacements, and in general all in tank or pit work. Other types of maintenance are marginal from the perspective of downtime contribution. (Figure 6-12)

\subsection{Recent Trends and Analysis (1997 to 1999)}

The previously described global maintenance and downtime contribution analyses were established over a relatively wide time frame (1993 to June 1999). While this provides the advantage of a larger database and hence more representative trends from a global and historical perspective, these trends may not necessarily reflect the current situation. Some specific maintenance actions or equipment failures of the past may not be encountered today because they have been eliminated through various improvements, modifications, alternate designs, or component replacements.

In order to eliminate this "historical bias" the same analysis was repeated over a more recent time frame. The period from 1997 to June 1999 was selected based on the following considerations:

- Many significant system or equipment design modifications were incorporated up until the end of 1996 primarily as a result of the lessons learned over previous years and appeared as a good "cut-off" point to eliminate "troublemakers" of the past.

- This reduced time period and hence reduced database, remains sufficiently large to yield significant trends.

- Some notable constraints, such as flammable gas monitoring or exhauster requirements are unique to the post 1996 period. 


\subsubsection{Global Maintenance Frequency and Time Distribution by Systems}

Five systems standout and account for $55 \%$ of the total maintenance frequency and $68 \%$ of total maintenance time. Although the overall distribution is not fundamentally different from the 1993-1999 time frame, some notable differences should be outlined: (Figure 6-13)

- The jet pump and discharge jumper assemblies remain the leading "culprits" but with a slightly lower relative maintenance time consumption ( $22 \%$ versus $34 \%)$.

- The leak detection system is in reality a specific and past issue. Extensive modifications related to the installation of MTL barriers in multiple tank farms account for the significant maintenance time consumption.

- Flammable gas monitor maintenance frequency and time consumption increase when considering recent times. The FGM problems are clearly a current and existing trend.

- The relative importance of transfer line plugging increases and clearly remains an existing problem.

- The maintenance frequency and time consumption associated to the dilution system reflects the relatively recent installation of this system in saltwell pump skids.

- The relative importance of problems associated with the level control function and its instrumentation decreases significantly primarily as a result of various upgrades and modifications to the system.

\subsubsection{Frequency and Downtime Contribution by Systems}

Systems which have more specifically and recently contributed to downtime rank as follows:

Table 6-3

Frequency and Downtime Contribution by Systems (1997-1999)

\begin{tabular}{|l|c|c|}
\hline & $\begin{array}{c}\text { Frequency } \\
(\%)\end{array}$ & $\begin{array}{c}\text { Downtime Contribution } \\
(\%)\end{array}$ \\
\hline Jet Pump and Discharge Jumper Assembly (PA) & 26.1 & 34.3 \\
\hline Flammable Gas Monitor (FGM) & 25.0 & 16.7 \\
\hline Plugging of Transfer Lines (TL) & 4.3 & 14.2 \\
\hline Dilution System (DS) & 14.1 & 12.1 \\
\hline Pump Control Station (PCS) & 3.3 & 6.9 \\
\hline Level Control Function (WFIE) & 8.7 & 5.6 \\
\hline \multicolumn{1}{|c|}{ Total } & 81.7 & 89.8 \\
\hline
\end{tabular}


Six systems contribute to $90 \%$ of equipment failure or maintenance related downtime. The differences between this recent trend and the one established from 1993 to 1999 are similar and consistent with the evolutions discussed in the previous section. (Figure 6-14)

\subsubsection{Critical Downtime Contributors}

This section addresses more specifically the components and failure modes, which have recently contributed to downtime. Seventeen individual components and usually specific failure modes constitute $87 \%$ of equipment failure related downtime, and $74 \%$ of failure/maintenance frequency. (Figure 6-15)

Further analysis shows that this list can actually be reduced further to 10 individual components who contribute to $70 \%$ of all equipment related downtime, if one eliminates those components whose failures have been either isolated events (low frequency) or historical but no longer occurring events.

Those components and/or failure modes that have been eliminated from further consideration based on these considerations include:

- Isolated failures of the pump control station hand switch ( 2 occurrences)

- Various problems with the early air compressors, which have now been corrected (5 occurrences)

- Modifications to adapt a line flush connection to the pump recirculation line (2 occurrences)

- Isolated failures with the dilution system pump motor, and minor piping leaks (4 occurrences)

- Various but minor problems with piping, valves, and fittings in the weight factor instrumentation cabinet (WFIE) (2 occurrences)

The remaining few components and failure modes which clearly deserve consideration from the perspective of reducing downtime are more explicitly described and discussed in the following section.

\subsection{Critical Components and Failure Modes - Discussion and Recommendations}

Critical components and failure modes are listed by decreasing order of importance based on their respective downtime contribution. 


\subsubsection{Plugging of Transfer Lines}

The plugging of transfer lines is a complex issue whose analysis was not attempted within the scope of this study. As the single leading downtime contributing failure mode however, it may be worthwhile to identify with the Process Engineering organization whether any aspects of this problem hold potential for a better understanding and mitigation:

- Specific waste rheology and process conditions (flow velocity, dilution rates, temperatures)

- Alternative waste characterization and process testing approaches

- Optimized jumper piping geometry and configuration, etc...

Line unplugging tools and technologies should also be investigated

\subsubsection{JR and JP Valves}

Valve leaks and limit switch problems have dominated as the two primary failure modes on these valves. Leakages seem to have been primarily connected to installation (e.g. JR-1 stem torque adjustments) or shop fabrication control issues rather than valve design. The recommendation is to pursue the tightening of fabrication, shop testing and $\mathrm{QC}$ of these valves. Alternative valve design could be investigated in parallel.

Magnetic proximity switches are now replacing the older mechanical limit switches and seem to provide a more reliable and accurate position indication. It seems however, that some design improvement to the flags/target for these proximity sensors is still needed. A more minor mechanical problem requiring attention includes a modification (remote valve stop or other means) to prevent application of excessive torque to valve handle. These handles frequently bend or shear off the valve stops or funnels when valves are actuated.

\subsubsection{Jet Pump and Motor Assembly}

Pump gasket leaks and burning out of motors seems to have been the dominant failures associated with the jet pump and its motor assembly. Difficulties encountered in the pump's operation seem to be related to priming and plugging of the foot valve.

A number of modifications over time have eliminated some of the earlier problems with the jet pump and its motor such as the installation of suction and discharge pressure measurements and bearing temperature monitoring.

Short-term modifications warranting attention include:

- The need for a new jet-pump chamber with a tighter assembly QC control, as the older casings are apparently no longer made. 
- Ambient cooled motors rather than process fluid cooled bearings. Bearing cooling lines clog and require flushing. The cooling fluids properties change (specific gravity, solids concentration). Pump bearing performance cannot accurately be tested.

- Improved pump and motor access pump pits to facilitate maintenance. Tanks to be pumped in the future seem to have larger pump pits allowing an optimized pump installation and access.

- Foot valve design (plugging) and physical protection.

Consideration should also be given to an alternative pump technology. A simpler, more reliable, and higher capacity pump design could perhaps be justified with tanks A-101 and AX-101 where a large volume of free supernate is present.

Two candidate technologies seem to warrant evaluation such as the AEA fluidic pump or a screw type positive displacement pump (no priming required) with pressure regulation. This evaluation however needs to clearly establish risk and the overall cost benefit of these alternative technologies, considering the limited number of tanks remaining to be stabilized.

\subsubsection{Pump Jumper Pressure Switches (PS-1 and PS-2)}

Frequent failures of the older pressure switches seem to have been somewhat mitigated by recent modifications such as the replacement of PS-2 by in-pit transducer and coupling (?) of a transducer to PS-1.

\subsubsection{Pump Discharge Jumper}

Jumper leaks have apparently been reduced by tightening leak testing acceptance criteria. The pressure rating of the jumper has also been increased in order to facilitate unplugging.

\subsubsection{Dilution System}

Most of the earlier problems with the dilution system seem to be connected to the pump motor and various piping leaks. These however were isolated events. Manual flow control with the existing rotameter seems to be erratic, unstable and lacking the required flow precision. There is clearly a need for better dilution flow control. Some of the future tanks with difficult waste will furthermore require high dilution ratios.

It is not too clear however whether the solution lies in a better installation of the flow meters (e.g. regulating the flow on the outlet side rather than inlet side of the flow meter) or resorting to an alternative type of flow controlling element. Another approach could be to consider metering pumps. 


\subsubsection{Level Control Function and WFIE}

Three items deserve attention based on their respective failure frequency:

- Plugging of Dip Tubes: It would seem, based on discussions with operating staff, that this is generally connected to a poor control of the water addition to the tubes (used to prevent salt/sludge clogging) rather than a fundamental design problem. Minor adaptations may be used to improve this control.

- Electro-Pneumatic Converter (EPC): Failures of the EPC seem to be dominantly connected to drifting of its calibration or PID loop parameters. The plugging of the air relay also appears as a recurring problem. The nature of these problems seems to suggest that an alternative type of converter (hardened and with possibly self-tuning capabilities) should be considered. Alternatively a reinforced preventive maintenance schedule of the existing converter could be considered.

- Weight Factor Transmitter (WFT): The exact nature of the failures remains unclear. The transmitter has apparently been replaced each time it failed. Further investigation is needed.

\subsubsection{Flammable Gas Monitor (FGM)}

Two distinctive sets of problems and failures associated to the flammable gas monitor were identified. The first set is generic failures primarily associated to the standard FGM model. The other set of problems is unique and specific to the three new and recently deployed FGM 4.46 models.

Dominant problems with the standard FGM unit were apparently related to:

- The catalytic bead combustion sensor failures

- Flow indication

- Operation of the confidence loop

- Sample valves failure

- Abnormally frequent test gas bottle changeouts.

The frequency of these problems has apparently decreased with recent times. The more recent FGM problems associated to the 4.46 model generally seem to result from a rushed deployment, and more specifically the inadequate testing of its operability. Some of these specifically include:

- The inability to maintain vacuum, or instability of settings and adjustments apparently resulting from a combination of various leaks, and inadequate vacuum control. The later may be caused by an incorrectly sized pressure regulating valve. Alternatively a simpler control scheme similar to the older FGM models could be considered (vacuum pump operating at fixed rate). 
RPP-5129

- Manufacturing defects in the MMI screens

- Rotameter and solenoid valve failures

- Limited capacity of test gas bottles apparently resulting from leaking brass to stainless steel connections.

A comprehensive and methodic troubleshooting and testing program for these new FGM units seems to be required. Parallel use of an inactive test loop in the shop may be worth considering in order to facilitate this process.

\subsection{OTHER UNPLANNED SHUTDOWNS}

Aside from equipment failures, other types of unplanned shutdowns also contribute to downtime as described in Section 3.3. These include:

- Shutdowns by interlocks, trips, and alarms

- Operational Restrictions due to external events or activities

- Administrative restrictions due to safety or regulatory issues

For reasons given in Section 3.5, no attempt was made within the scope of this study to quantify and analyze these downtime contributing elements. The following elements of information however were obtained in discussions with IS staff regarding frequent nuisance tripping elements:

- Shutdown by interlocks

- Priming of the jet pump

- Loss of pump suction pressure with high dilution rates

- Plugging of foot valve

- Heat trace electrical panels

- Leak detection in rainy weather

The downtime contribution of these elements is currently suspected to be largely underestimated. These frequent nuisance tripping elements should be quantified and analyzed. This could be obtained through a review of existing operational records (if the relevant information can be found) or instituting a specific logging and recording of these events by shift operations. 


\subsection{PLANNED SHUTDOWNS ANALYSIS}

\subsection{Downtime Contribution Estimation}

During each saltwell pumping campaign, the pump must be shut down periodically to accomplish several routine activities that support the pumping operation. Downtime contribution of routine shutdowns has been established in the following sections.

\subsubsection{Weekly Flushes}

During saltwell transfers, procedures require the pump to be shut down no less than once per week to flush the transfer lines (to prevent solids precipitation plugging the lines). These weekly line flushes require on 8 -hour shift per week. $8 \mathrm{hrs} / 168 \mathrm{hrs}$ per week $=4.8 \%$ downtime.

\subsubsection{Saltwell control System PMs}

Routine maintenance and calibration of the various components of the saltwell pumping control system requires an average of 160 hours per year, or $2 \%$ downtime.

\subsubsection{DCRT Transfers}

For those tanks pumping via a DCRT, periodic shutdowns are required to empty the receiver tank. Taking the 244-U DCRT as an example, the current planning model assumes a 20,000 gallon transfer volume, and a 24 hour shutdown for the transfer to be accomplished. Factoring in the volumes to be removed from each tank, and the number of tanks pumping concurrently, this results in an average of $10 \%$ downtime.

\subsubsection{DCRT Maintenance}

DCRT transfers are rarely accomplished within the 24 hours assumed in planning. In many cases, various DCRT maintenance activities must be completed first, requiring three to five days instead of one. In addition, although major corrective maintenance items cannot be planned for in detail, experience shows that approximately 15 days are required per year for these items. Historically, these factors combined have added over 15 to $20 \%$ additional downtime. By better coordination of planned maintenance activities, a $25 \%$ improvement in this area could reasonably be achievable over time. This provides an estimation of $15 \%$ downtime for DCRT preventive (PMs) and corrective maintenance.

\subsubsection{Annual Hydro Tests}

The direct buried segments of underground transfer lines are required to be revalidated by hydrotesting every 12 months. This requires a one week shutdown on average for a single tank. Multiple tanks pumping within the same transfer system (i.e., feeding the same DCRT) are tested concurrently where practical, but sometimes a pumping tank has to be shut down to support 
testing for another tank. On average this adds another 3 days to the annual shutdown requirement. 10 days $/ 365$ days per year $=3 \%$ downtime.

\subsection{Recommendations}

\subsubsection{DCRT Transfers and Maintenance}

DCRT transfers and maintenance alone represent an estimated contribution to downtime of 25 to $30 \%$, and clearly deserve primary attention as a mean of improving operating efficiency.

The ideal solution is clearly to bypass DCRTs, with alternative transfer routes, and/or use of overground transfer lines, and some operating and procedural adjustments such as the controls for waste mass balance accounting. Where alternative transfer routes cannot be found or used (e.g. head limitations), the DCRT could be used as a continuous transfer vessel rather than a batching tank. At the time of this study, most of the adaptations required to bypass DCRTs had been addressed in view of eliminating DCRTs from future transfer routes and hence no further analysis was performed on this aspect.

Alternative transfer routes will however increase interconnections to other active transfers and most likely introduce other potential sources for shutdown. This may partially offset the expected gain in operating efficiency and needs to be evaluated. A predictive RAM analysis of these alternative transfer routes is recommended.

\subsubsection{Other Routine Elements of Downtime}

Annual hydro tests and saltwell control system preventive maintenance do not seem to contribute sufficiently to downtime to warrant any further optimization.

Weekly flushes which constitute close to $5 \%$ of downtime could possibly hold potential for increasing operating efficiency with an evaluation on a case by case basis of their frequency. Considering however this marginal gain over the risk of line plugging and resulting downtime, this approach is not recommended. 


\subsection{MAINTENANCE INDICATORS AND TRENDS}

The objective of this section is to describe some of the maintenance indicators and trends identified during the review of JCS records. These have been examined from a global and statistical standpoint and would clearly require a finer interpretation and analysis in order to yield firm recommendations regarding potential maintenance practice and process improvements.

\subsection{Actual and Normalized Field Work Time}

In some instances, and as explained in Section 6.3, the duration during which a JCS package was left open for field work could not be used as a measure of the actual field work duration used for a specific work item. As a result, judgement was used in these specific cases to attribute a corrected (or normalized) field work duration. Although possibly arbitrary this was needed in order to eliminate the risk of a statistical bias in the analysis. Approximately $20 \%$ of the total 373 individual work items considered for this study were field time corrected. A comparison of the average actual and normalized field work time for the different sets of JCS data considered is presented in Table 9-1. 
$\frac{\text { 굴 }}{2}$

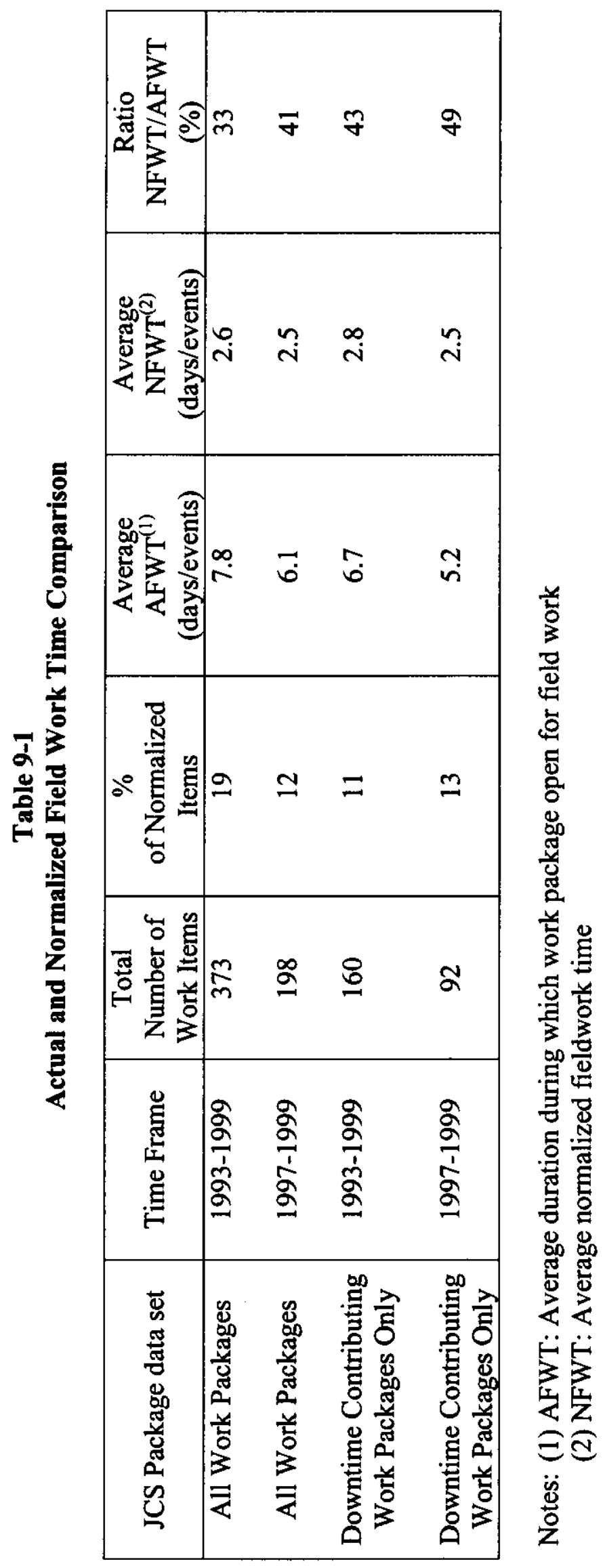


The following observations can be made regarding these results:

- The average duration during which a package is open for fieldwork ranges from 5.2 to 7.8 days per event depending on the nature of the maintenance work items and time frame considered.

- The average normalized fieldwork duration ranges from 2.5 to 2.8 days per event.

- The normalized to actual fieldwork time ratio increases if downtime contributing events alone are considered.

- In all cases the normalized to actual fieldwork time ratio has increased when a more recent time frame is considered.

- Packages with extended durations represent in all cases a small proportion of the total number of packages. The weight by duration of these packages is however significant.

A closer look at the individual work packages shows that the circumstances and reasons for having packages open for extended durations are multiple:

- Redirection of resources to higher priority tasks.

- Evolution or adaptation of the initial work scope of the package.

- Delays associated with the procurement of long lead components or time needed to salvage these components from another skid.

- External circumstances (weather, safety, or regulatory standdowns, etc...).

- A standard component replacement or modification which is being implemented on a series of tanks which are not simultaneously available for field work.

- In some isolated cases, the unsuccessful attempts to resolve the problem (e.g. unplugging of the SX-104 to $244 \mathrm{~S}$ transfer line segments).

\subsection{Distribution of Maintenance Types}

This section looks more specifically at the relative distribution of maintenance action types (corrective maintenance, modifications and upgrades, non-routine preventive maintenance, operations special procedures, non-routine tests and calibrations) and more specifically:

- From a global standpoint.

- Across the different phases (preparation, pumping, post-pumping) associated with saltwell pumping. 
- Within each one of these phases.

- For each of the individual saltwell systems.

Note: The (Figures) referred to in this section are graphs produced from the Excel database, which were included as an attachment to the letter report. They do not appear in this document.

\subsubsection{Global Distribution}

Maintenance of saltwell systems is largely dominated by corrective maintenance actions and in general a "run to failure" strategy. Whether this approach and level of corrective maintenance as opposed to an increased level of preventive and predictive maintenance is appropriate, requires consideration of the relatively short operational life required from saltwell systems versus the limited number of critical components which can potentially induce significant downtime.

(Figures 9-1 and 9-2)

The relatively low frequency and time dedicated to non-routine or "accidental" preventive maintenance tests and calibrations interrupting pumping would tend to indicate that the current routine preventive maintenance program (PMs) largely meets its intent. However, the preventive maintenance for some of the critical components identified in this study may deserve reevaluation.

\subsubsection{Maintenance Frequency and Time Distribution Across and Within the Different Phases}

Table 9-2 shows the distribution of maintenance frequency and time according to and within the different saltwell pumping phases: (Figures 9-3 through 9-6)

Table 9-2

Maintenance Frequency and Time Distribution by Phase

\begin{tabular}{|l|c|c|}
\hline & $\begin{array}{c}\text { Maintenance } \\
\text { Frequency (\%) }\end{array}$ & $\begin{array}{c}\text { Maintenance Time } \\
\text { Distribution (\%) }\end{array}$ \\
\hline - Preparation Phase & 25 & 33 \\
- During Pumping and Contributing to Downtime & 45 & 47 \\
- During Pumping but not Contributing to \\
$\begin{array}{l}\text { Downtime } \\
\text { - Post Pumping Phase }\end{array}$ & 27 & 16 \\
\hline \multicolumn{1}{|c|}{ Total } & 3 & 4 \\
\hline \multicolumn{1}{|c|}{} \\
\hline
\end{tabular}


Maintenance events contributing to downtime represent almost $50 \%$ of the global maintenance effort. Corrective maintenance performed during pumping whether or not contributing to downtime globally represents close to $45 \%$ of the overall maintenance effort. This is primarily described in Section 6.

\subsubsection{Maintenance Type Distribution by Systems}

The nature and distribution of maintenance actions for each of the individual saltwell systems are summarized in the following table for the key systems: (Figures 9-7 through 9-11)

Table 9-3

Maintenance Type and Time Distribution by Systems

\begin{tabular}{|l|c|c|c|c|c|c|c|c|}
\hline & \multicolumn{9}{|c|}{ Systems } \\
\hline \multicolumn{1}{|c|}{ Maintenance Type } & Total & PA & WFIE & FGM & TL & DS & LD & Others \\
\hline Corrective Maintenance & 58.4 & 24.2 & 9.1 & 6.2 & 0.7 & 3.4 & 0.7 & 14.1 \\
$\begin{array}{l}\text { Non-routine Preventive } \\
\text { Maintenance }\end{array}$ & 5.1 & 0.8 & 1.4 & 0 & 0 & 1.5 & 0.1 & 1.3 \\
$\begin{array}{l}\text { Modifications and } \\
\text { Upgrades }\end{array}$ & 25.6 & 6.0 & 2.5 & 1.3 & 0 & 0.2 & 8.0 & 7.6 \\
$\begin{array}{l}\text { Operations Special } \\
\text { Procedure }\end{array}$ & 8.4 & 2.2 & 0.2 & 0 & 5.7 & 0 & 0.3 & 0 \\
$\begin{array}{l}\text { Non-routine Test and } \\
\text { Calibrations }\end{array}$ & 2.6 & 0.6 & 0.7 & 0.7 & 0 & 0 & 0 & 0.6 \\
\hline \multicolumn{1}{|c|}{ Total } & 100 & 33.8 & 13.9 & 8.2 & 6.4 & 5.1 & 9.1 & 23 \\
\hline
\end{tabular}

\subsubsection{Recommendations}

Further investigation is recommended in order to:

- Pursue the analysis of these indicators and trends

- Determine for the identified critical systems/components whether an increased level of preventive/predictive type of maintenance can offer an advantage. 


\subsection{OPERATION AND MAINTENANCE PROCESS CONSIDERATIONS}

The following observations, suggestions and recommendations on how to possibly optimize the operation and maintenance of saltwell pumping systems were primarily collected during discussions with IS Operations, Engineering and Maintenance personnel.

\subsection{Potential Relaxation of Safety Requirements}

\subsubsection{Dual Flammable Gas Monitoring Requirements}

The tanks currently being pumped could possibly provide enough data between SHMS and FGMs to reasonably show that the environments inside and outside the saltwell screen do not significantly vary. An engineering analysis could be considered for the elimination of the requirement to have both units operational. This could potentially decrease downtime associated with the maintenance of these units as well as simplify future tank stabilization in eliminating a full set of monitoring equipment for saltwells installed into SHMS monitored tanks.

\subsubsection{Exhauster Requirements}

A similar approach could be conceived with the objective of relaxing standby exhauster requirements for some of these tanks.

\subsection{Procedures and Administrative Aspects}

\subsubsection{Procedure Revision}

Pumping procedures are adapted from a standard and generic procedure. Frequently changing parameters (process parameters, set points, etc...) seem to be systematically addressed through a somewhat cumbersome and time consuming change process. It has been suggested that some of these parameter changes could be incorporated in a more flexible and rapid manner through process memos or redlining.

\subsubsection{Elimination of the Transfer Control Checklist}

A suggestion was made to hard copy data that only changes annually into the procedures, use a process memo setting pumping limits for a whole campaign and a monthly check of the data by an engineer. 


\subsubsection{Removal of Redundant Engineering Signatures}

A number of engineering signatures could possibly be hard copied in procedures or included in process memos for data that does not change very often. This would provide the additional flexibility of re-starting a pump at night for instance without additional Engineering acceptance.

10.2.4 Eliminate the practice of field testing instruments for pump start-up where they are already in use by another active transfer

Credit should be taken for the functionality of an instrument recently tested by another active transfer, and testing limited to the portion of the instrument loop specific to the pump system having started (e.g.: simulating a signal from the connection box to the PLC, rather than retesting the whole loop from the sensor).

\subsection{Training}

It was indicated that some differences still subsisted between the different shifts in their ability to maintain the pump in operation, or in handling some of the more recent systems or components (e.g.: FGM), and that more training should be considered.

\subsection{Shift Operation and Engineering/Maintenance Interface}

A number of suggestions were made in view of enhancing the interface between field operations and Engineering/Maintenance:

- The need for a more formal and documented problem description and troubleshooting process in order not to loose valuable information.

- A more direct line of communication.

- Dedicating a crew to perform troubleshooting and maintenance of pumps in operation in support of shift operations.

- Developing and maintaining a list of all interlock and set point statuses for shift operations.

- Improving the clarity and ease of interpretation of process memos.

- Detailed logging of circumstances and operational parameters associated to shutdowns. 


\subsection{CONCLUSIONS AND RECOMMENDATIONS}

The duration of the SST IS Project is directly affected by the total system availability of the pumping system. The current IS project plan projects an average of 45 to 50 percent availability of the saltwell pumping system. For tanks with long pumping durations, increased operating efficiency can result in dramatic improvements to the overall completion schedule, and life-cycle cost savings. The primary findings of this analysis of the reliability, availability and maintenance (RAM) of saltwell pumping systems indicate that:

- The average operating efficiency of saltwell pumping systems from 1993 to 1999 is estimated at 42 percent.

- The average operating efficiency for tanks currently in operation and considered since June 1998 is 34 percent (as of June 27, 1999).

- Two elements clearly dominate as downtime contributors and offer the most potential for substantial and short term gain:

- DCRT transfers and maintenance estimated at 25 to 30 percent

- Saltwell equipment failures and maintenance estimated at over 20 percent

- Six systems contribute to $\mathbf{9 0}$ percent of equipment failure and maintenance related downtime

- A limited number (10) of individual components within these systems and specific failure modes have been identified as contributing to 70 percent of equipment failures and maintenance related downtime. These critical components clearly deserve priority for short-term increase of the operating efficiency.

As a result of these findings a number of recommendations specifically related to these elements as well as other aspects were identified in order to achieve increased system operating efficiency and/or lower operating and maintenance costs. The following is a summary and prioritized list of these recommendations.

\subsection{Bypass of DCRTs}

A substantial gain in operating efficiency can be targeted by bypassing DCRTs through alternative transfer routes, and/or use of overground transfer lines. Continuous transfer rather than batching through DCRTs can also be considered, where alternative routes cannot be found. Alternative transfer routes will however increase interconnections to other active transfers and most likely introduce other potential sources for shutdown. This may partially off-set the 
expected gain in operating efficiency and needs to be evaluated. A predictive RAM analysis of these transfer routes is recommended.

\subsection{Critical Components}

A substantial gain in operating efficiency can be targeted in improving the reliability of these components. These components, their failure modes, as well as the possible means of improving their reliability are specifically identified and described in Section 6.8. Most of these recommendations imply relatively simple and practical actions such as alternative component specifications, modifications, improved fabrication control, testing, or installation.

- JR and JP Valves

- Tighten fabrication tolerances, shop testing, QC, etc...

- Alternative valve design

- Jet Pump and Motor Assembly

- New jet pump chamber

- Ambient cooled motors

- Improved pump and motor access in larger upcoming pits

- Evaluate Alternative pump technologies

- PS-1 and PS-2

- Recent modifications have eliminated most problems

- Pump Discharge Jumper

- Tighten fabrication tolerances, shop testing, QC, leak test acceptance criteria, etc..

- Investigate recent jumper pluggings

- Dilution System Flow control and Precision

- Modify rotameter installation, consider alternative flow element, or metering pump

- WFIE

- Plugging of dip tubes: water addition control issue rather than design issue

- EPC: Replace by hardened converter with self tuning capabilities or reinforce PM frequency of existing EPC

- WFT: failure mode remains unclear 
- FGM

- Standard model issues (Sensor, FI, Confidence loop, Sample Valves, test bottle change-outs)

- FGM 4.46 Issues (Vacuum control and multiple post-installation problems)

- Comprehensive and methodic field troubleshooting and testing program. Combine with parallel inactive test loop in shop (Engineering Laboratories?).

\subsection{Spare Parts Management}

Revisit and update as applicable the spare parts list based on the previous identification of critical components.

\subsection{Engineering Documentation}

Consider the need and benefits of a more structured and systematic engineering file:

- List of interlocks and set points for all skids

- Equipment and instrument lists

- As-build essential drawings, etc...

\subsection{Interlocks, Trips, and Alarms}

Quantify and analyze shutdowns by interlocks, trips, and alarms by review of existing operational records and/or specific logging and recording during shift operations.

\subsection{Process Engineering Aspects}

- Update volume and drainage rate predictions based on an evaluation of recent waste and operational data

- Investigate alternative approaches to line plugging characterization and mitigation

\subsection{Technology}

- Evaluate alternative pump technologies

- Pursue evaluation of selected (i.e.: low cost impact) alternatives, technologies or enhancements, identified in the IS Project Plan (Lewis 1999, Appendix B). 


\subsection{O\&M Process Considerations}

- Dedicate a maintenance crew in support of field operations

- Operator Training

- Establish a more direct line of communication between field operations and Engineering and Maintenance

- Explore means to simplify procedure revisions

- Enhanced use of JCS for RAM indicators and trending

\subsection{Potential Relaxation of Safety Requirements}

- Investigate potential avenues for the relaxation of the following requirements based on operational data and engineering analysis:

- Standby exhauster

- Dual flammable gas monitoring 


\subsection{REFERENCES}

DeFord, D. K., 1998, SST Interim Stabilization Project Considerations for Determining a Target "Pumping Percentage" Rate for Saltwell Pumping (unpublished), Lockheed Martin Hanford Corporation, Richland, Washington.

Lewis, J. G., 1999, Single-Sell Tank Interim Stabilization Project, HNF-2358, Rev. 3a, Lockheed Martin Hanford Corporation, Richland, Washington.

LMHC, 1999, SST Interim Stabilization Project Performance Bi-monthly Report, dated June 27, 1999, Lockheed Martin Hanford Corporation, Richland, Washington.

LMHC, 1999, Tank Farm Operating Procedure, "241-S and 241-SX Farm Single-Shell Tanks to 241-SY-102 Double-Shell Tank Saltwell Pumping," TO-420-100, C-0, dated June 24, 1999.

LMHC, 1999, Saltwell System Operations Training Guide, Revision 3, Course Number 350080, Lockheed Martin Hanford Corporation, Richland, Washington.

McVey, C. B., General Saltwell Spare Inventory List, (DSI, D. J. Saueressig, dated September 26, 1997, Lockheed Martin Hanford Corporation, Richland, Washington.

Raymond, R. E., 1991, Jet Pump Duration to Interim Stabilize Remaining Single-Shell Tanks, (External Letter to R. E. Gerton, DOE, 9152682 R3, dated November 11, 1991), Westinghouse Hanford Company, Richland, Washington.

Schreiber, R. D., 1998, Jet Pump Duration for Interim Stabilization of Remaining Single-Shell Tanks, (Internal Memorandum to J. O. Honeyman, 7A150-98-014, dated March 17, 1998), Lockheed Martin Hanford Corporation, Richland, Washington.

Schreiber, R. D., 1998, Updated Jet Pump Durations for Interim Stabilization of Remaining Single-Shell Tanks, HNF-2978, Rev. 0., July 1998, Lockheed Martin Hanford Corporation, Richland, Washington.

Vasquez, V. J., 1994, Jet Pump Duration to Interim Stabilize Remaining Single-Shell Tanks, (DSI to V. C. Boyles, dated July 13, 1994), Richland, Washington.

Wiggins, D. D., Single-Sell Tank Leak Emergency Guide, HNF-SD-WM-AP-005, Revision 6, Lockheed Martin Hanford Corporation, Richland, Washington. 